\title{
A Ionga paz na América do Sul: questionamentos às teses da paz negativa na região*
}

\author{
The Long Peace in South America: Questions \\ about the Thesis of Negative Peace in the Region
}

\section{La extensa paz en América del Sur: críticas a las tesis de la paz negativa en la región}

\author{
Rafael A. Duarte Villa** \\ Marilia Carolina B. de Souza Pimenta***
}

Recibido: 31 de octubre de 2016

Aprobado: 28 de noviembre 2016

Disponible en línea: 20 de diciembre de 2016

\section{Resumo}

$\mathrm{O}$ artigo procura tensionar narrativas teóricas relevantes para a formação de de um discurso de paz negativa en América del Sur. Metodologicamente, discute de forma crítica a maneira como algumas epistemologias, especialmente da Escola Inglesa e Liberal Institucionalista, focam o tema da construção da paz negativa na América do Sul ao mesmo tempo que se apresentam as tensões, contradições e principais contribuições dessas epistemologias. A seguir, as narrativas discutidas são contrastadas com desenvolvimentos empíricos na região relacionados com o tema da paz negativa. Entre os achados

\section{Abstract}

The article challenges relevant theoretical narratives on the formation of a discourse on negative peace in South America. Methodologically, the article critically analyzes the way in which some epistemologies, especially those from the English School and Liberal Institutionalist perspectives, focus on the construction of negative peace in South America, while the tensions, contradictions and main contributions of such epistemologies are shown. These narratives are then contrasted with empirical developments in the region related to the theme of negative peace. Among the most important

\section{Resumen}

$\mathrm{El}$ artículo tensiona narrativas teóricas relevantes para la formación de un discurso sobre paz negativa en América del Sur. Metodológicamente, se analiza la forma en que algunas epistemologías, en especial las de la Escuela Inglesa e Institucionalista Liberal, enfocan el tema de la construcción de la paz negativa en América del Sur, al mismo tiempo que se muestran las tensiones, contradicciones y principales contribuciones de tales epistemologías. A continuación, estas narrativas se contrastan con desarrollos empíricos en la región relacionados con el tema de la paz negativa. Entre

doi:10.11144/Javeriana.papo21-2.Ipas

* Artículo de reflexión.

** Instituto de Relações Internacionais da Universidade de São Paulo (São Paulo, Brasil). Contact: rafaelvi@usp.br *** Núcleo de Pesquisas em Relações Internacionais da Universidade de São Paulo (NUPRI) (São Paulo, Brasil) Contact: profa.marilia.csouza@gmail.com 
mais importante se enfatiza que as narrativas tradicionais sobre a paz negativa não prestam atenção a pesquisas empíricas sobre violência político-social doméstica na América do Sul, sendo muito orientadas, tais perspectivas, para uma noção de paz que privilegia ainda uma visão interestatal da sociedade internacional sul-americana; em segundo lugar, as narrativas tradicionais sobre paz na América do Sul são também tencionadas quando se atenta para a nem sempre diferenciação de políticas de segurança e defesa na região. Finalmente, ao examinar alguns índices internacionais sobre violência e políticas públicas em estados sul-americanos percebe-se uma ambivalência conceitual porque ao mesmo tempo que as narrativas tradicionais fazem uma contribuição importante quando resgatam, analiticamente e empiricamente, a sociologia histórica , de outro lado, excluem uma reflexão sobre o impacto da violência social na formação de um "Estado forte" e no efeito transnacional da violência de grupos não estatais violentos.

\section{Palavras-chave}

América do Sul; segurança; paz; violência; guerra; conflitos findings, the article points out that the traditional narratives about negative peace do not pay attention to empirical research on domestic political and social violence in South America. Such perspectives are strongly oriented by an understanding of peace that continues to favor an interstate narrative on the South American international society. Second, traditional narratives of peace in South America are also challenged when they pay little attention to a not always clear differentiation between security and defense policies. Finally, when examining some international indices on violence and public policies in the South American states, a conceptual ambivalence is perceived because while traditional narratives bring an important contribution when they rescue, analytically and empirically, historical sociology, on the other hand, they exclude a reflection on the impact of social violence on the formation of a "strong state" and the transnational impact of violent non-state groups.

\section{Keywords:}

South America; security; peace; violence; war; conflict

\section{Cómo citar este artículo:}

Duarte-Villa, R. A. y de Souza Pimenta, M. C. B (2016). A longa paz na América do Sul: questionamentos às teses da paz negativa na região. Papel Político, 21(2), 435-468. https://doi. org/10.11144/Javeriana.papo21-2.lpas

los hallazgos más importantes, se destaca que las narrativas tradicionales acerca de la paz negativa no prestan atención a la investigación empírica sobre la violencia política y social interna en América del Sur, siendo muy orientadas tales perspectivas por una comprensión de paz que sigue favoreciendo una narrativa interestatal sobre la sociedad internacional sudamericana. En segundo lugar, las narrativas tradicionales de la paz en América del Sur también se tensionan cuando se presta atención a la no siempre clara diferenciación entre políticas de seguridad y defensa. Por último, al examinar algunos índices internacionales sobre violencia y políticas públicas en los estados de América del Sur, se percibe una ambivalencia conceptual, porque, mientras aquellas narrativas tradicionales consiguen realizar una contribución importante al rescatar, analítica y empíricamente, la sociología histórica, por el contrario excluyen una reflexión sobre el impacto de la violencia social en la formación de un "estado fuerte" y el impacto transnacional de grupos no estatales violentos.

\section{Palabras clave}

América del Sur; seguridad; paz; violencia; guerra; conflicto 


\section{Introdução}

Algumas análises sustentam que a maioria das elites civis e burocracias de formulação de políticas externas na América Latina, bem como corpos diplomáticos aderem à lógica da paz permanente e contam com a diplomacia e o direito internacional para resolver disputas interestatais (Pion-Berlin e Trinkunas, 2007, pp. 76-100). De igual forma, as práticas de paz permanente na América Latina têm sido favorecidas por longos períodos em que as guerras entre estados desaparecem da história militar da região. A última grande guerra aconteceu entre Bolívia e Paraguai (a guerra do Chaco, que teve lugar em 1932-1935).

Essa longa ausência de grandes conflitos violentos entre estados latino-americanos provavelmente tem levado à convicção dos formuladores de política externa de governos da região de acordo com a qual seus vizinhos não seriam ameaças para a existência de seus estados, e por isso, a modernização das suas capacidades militares não teriam objetivos ofensivos. Conforme têm sustentado Pion-Berlin e Trinkunas: "Civis não acreditam que seus vizinhos são ameaças, porque a história tem mostrado que seus vizinhos raramente atacam. Assim, eles prestam pouca atenção para a política de defesa e evitam um forte financiamento militar”. (Pion-Berlin e Trinkunas, 2007, 7, tradução nossa).

Contribui também para a percepção de que há práticas mínimas de paz permanente na região, o fato de que, embora várias disputas territoriais não tenham sido resolvidas (ex. Colômbia e Venezuela; Bolívia e Chile; Chile e Peru; Colômbia e Nicarágua), tais disputas não parecem suficientemente intensas para gerar uma dinâmica de conflito interestatal violento. Por outro lado, mesmo existindo conflitos territoriais não resolvidos não há experiências na história latino-americana do surgimento de estados expansionistas territoriais, como no caso europeu dos séculos XVIII a XX. Talvez por esta razão, alguns estudiosos apontam que mesmo atores estatais, com significativas capacidades de poder na região, como no caso do Brasil, se tornem exemplos de países que emergem no cenário internacional praticando um revisionismo soft, quer dizer, promovendo mudanças internacionais no sistema multilateral de governança, em vez de promover doutrinas ou práticas de expansão ou anexação territorial (Bernal-Meza, 2010).

Este artigo tensiona diferentes narrativas sobre a natureza da paz permanente na América do Sul, e se divide em duas seções principais: na primeira se discutem de maneira crítica diferentes concepções e epistemologias que tem abordado o tema da construção da paz na América do Sul, especialmente da paz negativa, e ao mesmo tempo se mostram as tensões, contradições e principais contribuições dessas epistemologias; já na segunda parte tensionam-se propriamente as narrativas discutidas na seção anterior à luz dos desenvolvimentos empíricos da região relacionados com o tema da paz negativa. Finalmente, se introduz uma seção de considerações finais, em que se faz um rápido apanhado da contribuição trazida pelo artigo. 
Nesta última seção se exploram os principais achados e argumentos do artigo que podem ser listados da seguinte forma: em primeiro lugar, narrativas tradicionais sobre a violência na América do Sul, a exemplo da Escola Inglesa e a Institucionalista Liberal, não prestam atenção em pesquisas empíricas aos desdobramentos da violência políticosocial doméstica na América do Sul, e os impactos que esses aspetos têm na reflexão teórica e em políticas públicas. As suas narrativas continuam ainda muito voltadas para uma noção de paz negativa que privilegia ainda uma visão inter-estatal sul-americana; em segundo lugar, as narrativas tradicionais sobre paz na América do Sul são também tencionadas quando se atenta para clara diferenciação de políticas de segurança e defesa na região. Nesse sentido, as temáticas relacionadas aos conselhos da UNASUL e dos investimentos militares mais recentes mostram como as narrativas epistémicas sobre a paz negativa podem ser tensionadas. e, finalmente, atenta-se para a contribuição que sob uma perspectiva de sociologia histórica narrativas tradicionais deram para explicar a formação dos mecanismos causas na região como uma zona de paz porém tenciona-se mais uma vez tais narrativas. Por outro lado, ao examinar alguns índices internacionais sobre violência e políticas públicas em estados sul-americanos percebe-se uma ambivalência conceitual porque ao mesmo tempo que tais narrativas, sobretudo no caso da Escola Inglesa e do Institucionalismo Liberal, fazem uma contribuição importante ao resgata analiticamente e empiricamente a sociologia histórica, se exclui uma reflexão sobre a violência social e o impacto em: i) na formação do que tais perspectivas chamam de um "Estado forte" e, ii) no efeito transnacional da violência de grupos não estatais violentos na qualidade da sociedade anárquica sul-americana.

Por outro lado, a sua maior contribuição, pode ser também seu maior calcanhar de Aquiles teórico pelo que evidencia e em seguida excluiu. e o que se exclui é uma reflexão sobre a violência social e seu impacto perante a formação do Estado forte e sobre o efeito transnacional da violência de grupos não estatais violentos, realidade essa que acaba afetando, por fim, a qualidade da sociedade anárquica sul-americana.

\section{As narrativas da Zona de Paz para a América do Sul}

Ao longo das últimas duas décadas e meia, tem havido uma robusta produção de trabalhos teóricos, a maior parte, relacionada ao fenômeno da "longa paz", paz negativa, paz híbrida e comunidades de segurança na América do Sul. (Holsti, 1996; Kacowicz, 1998, 2005; Mares, 2001, 2012; Buzan e Weaver , 1998, 2003, 2009; Miller, 2007; Olesner, 2007; Merke, 2011; Battaglino, 2012¹). O objetivo desta seção é demostrar

\footnotetext{
${ }^{1}$ Battaglino apresenta uma variação dessa discussão. O autor desenvolve a hipótese da América do Sul como uma zona de paz híbrida que é "caracterizada pela presença simultânea de: (1) as disputas não resolvidas que podem tornar-se militarizadas, mas sem a escalada de um conflito armado intermediário ou guerra; (2) [Presença] de democracias que mantêm relações econômicas densas com os seus países vizinhos; e (3) normas e instituições regionais (antigas e novas) que ajudam a resolver disputas pacificamente. Os casos mais
} 
como tais narrativas e suas diferentes epistemologias ora se sobrepõem, ora se afastam, ou se complementam em relação à ideia de construção da paz na América do Sul, com vistas a aproveita-las na terceira seção, para mostrar as tensões que se derivam quando confrontadas com os dados empíricos que se extraem da América Latina. Certamente, alguns autores e suas narrativas serão priorizados na discussão desta e da seguinte seção.

Sob uma perspectiva histórica, diferentes epistemologias científicas têm abordado o tema da paz permanente na América do Sul, tentando explicar as causalidades e as especificidades ontológicas dessa paz. Uma das mais destacadas tem sido a perspectiva da Escola Inglesa, na versão racionalista e/ou construtivista. Autores como Kalevi Holsti (1996), Arie Kacowicz (1998; 2005) e Miller (2007) numa versão mais construtivista/ solidarista da Escola Inglesa e Buzan and Waever (2003), numa versão que mescla realismo e construtivismo, têm focalizado o fenômeno da paz na América do sul. Esse grupo de autores compartilha a ideia legada por Hedley Bull (2002) da América do Sul como sendo uma sociedade internacional (uma sociedade de estados) ou de comunidades políticas independentes, as quais não meramente formam um sistema, no sentido de a conduta de cada estado é um fator necessário nos cálculos dos outros, mas também estabelecem: i) um diálogo em torno de regras em comum; ii) consentimento e instituições para regular suas relações , e, iii) reconhecem um interesse comum em manter esses arranjos. No entanto, a análise dos argumentos mostra tanto pontos de coincidências quanto de afastamento entre eles.

Kalevi Holsti, numa versão da Escola Inglesa que mescla racionalismo e solidarismo, apresenta a seguinte problemática: levando-se em conta que a periferia não completou seu ciclo de desenvolvimento e, por conseguinte, se tornaria palco dos conflitos contemporâneos internacionais, uma região parecia apresentar uma anomalia, qual seja a América do Sul, pois, embora esta tenha presentes tanto aspectos de motivações convencionais para a guerra, quanto elementos conflitivos, a região observou um longo período de paz, ou de ausência de guerras prolongadas, durante século XX (1996, p. 152).

Importante afirmar que no século XIX houve uma série de conflitos com padrões tipo guerra versus paz, intervenções, disputas territoriais, alianças, corrida armamentista e balança de poder. Entretanto, não emergiu um grande estado expansionista, como no caso Europeu ocidental, que entre os séculos XIX e XX presenciou a emergência de estados geopoliticamente expansionistas como a França, Rússia e a Alemanha. Porém, se o expansionismo militar esteve ausente, houve sim, em compensação, disputas territoriais, geralmente em zonas de fronteira, mas estas, salvo algumas exceções, não levaram ao conflito prolongado. Assim, para Holsti:

relevantes da paz híbrida na América do Sul são Chile-Peru desde 1990 e Colômbia- Venezuela desde 1991". (Battaglino, 2012, p. 142; tradução nossa). 
O problema era que as formidáveis barreiras geográficas de áreas periféricas da América do Sul tornaram difícil a precisa demarcação das fronteiras [...] Vastas regiões da América do Sul, de qualquer modo, não foram cuidadosamente mapeadas durante o período colonial luso-espanhol. Tais regiões incluíam a Amazônia e bacias do rio Orinoco, Patagônia, Terra do Fogo e o deserto do Atacama - todas áreas de guerra e conflito nos séculos XIX e XX. [...] Muitas das regiões disputadas eram escassamente povoadas e de difícil controle, mas uma vez que elas foram descobertas como forma de manter os recursos para abastecer o comércio mundial, se tornaram palco de conflitos, crises e guerras (1996, pp. 153-154, tradução nossa).

Entretanto, este período não se manteve como lógica funcional na segunda metade do século XX e a região experimentou uma excepcional capacidade de resistência às guerras, e de resolução de disputas por meio de negociações diplomáticas. O raciocínio seria, portanto, identificar uma linearidade gradual em torno da construção de uma comunidade pluralista de segurança, a exemplo do que ocorreu na Europa, como preconizado por Karl Deutsh (1957).

Ocorre que, de forma híbrida, e esta é a principal contribuição que traz a reflexão racionalista de Holsti, a região avançou para uma zona de não guerra, ou paz negativa; pois houve uma série de incidentes militarizados e guerras de média intensidade em ocasiões distintas, como os conflitos entre Peru e Equador em 1981 e 1995, além de existir na região, de forma recorrente, mobilização das forças armadas nas fronteiras $^{2}$, bem como interrupção das relações diplomáticas entre os países: pressupostos inaceitáveis em uma Zona de Paz ou Comunidade Pluralista de Segurança (Holsti, 1996, pp. 158-160). A Zona de Não Guerra seria, sob uma perspectiva geopolítica, explicada pela "irrelevância” mútua entre os países da região, ou seja, eles não seriam interdependentes o suficiente para gerar uma base conflitiva mais acentuada, mas por outro lado, não praticam formas de sociedade internacional o suficientemente intensa para se avançar rumo à Zona de Paz.

A limitação conceitual do enfoque racionalista de Holsti deriva do fato de que ele não descrever quais os mecanismos causais que permitem gerar a zona híbrida de não guerra (Bataglino, 2012), em que mecanismos pluralistas de resolução de conflito convivem com tensões militarizadas. Além disso, aquele tipo de análise racionalista da escola inglesa parece repetir a mesma falha de teóricos da mesma linhagem, como o próprio Bull (2002), para quem a sociedade internacional específica (aquela que é analisada em particular) é pouco dinâmica, quase estática, não prevendo os mecanismos que permitiriam a superação do estágio atual (de zona de não paz) da sociedade internacional.

2 David Mares chega a contabilizar 17 incidentes militarizados na América Latina entre 2005 e 2011, dos quais 13 incluem algum país sul-americano (Mares, 2012). 
A contribuição de Kalevi Holsti se sobrepõe, de alguma maneira, à de Ariel Kacowicz (1998). Este último autor, fundado numa epistemologia solidarista e sociológica da Escola Inglesa, expõe padrões explicativos para o fenômeno anômalo da paz em duas regiões específicas do então chamado Terceiro Mundo: a América do Sul (desde 1883), e a África Ocidental (a partir da década de 60). Também ambos os autores coincidem em definir a América do Sul como uma região de paz negativa. No entanto, o argumento de Kacowicz se distancia do argumento de Holsti na percepção do conteúdo ontológico da anomalia, ao afirmar: "Assim, a anomalia é restrita à dimensão das relações internacionais, não à falta de violência política em geral” (Kacowicz, 1998, p. 70, tradução nossa).

Tanto Holsti (1996) quanto Kacowicz (2005) supõem que a exceção para condutas de warfare da América do Sul pode ser explicada por uma série de fatores institucionais peculiares da cultura e sociologia política histórica e regional. Para ambos os autores, a forte tradição jurídica, a tradição diplomática e o desenvolvimento de mecanismos de solução pacífica de controvérsias, frequentemente por meio da mediação e arbitragem internacional, foram os elementos que vieram a possibilitar esta incomum paz sulamericana, a despeito da existência de estados relativamente fracos na região até ao menos o final da Guerra Fria. A este fenômeno de influência das normas pacificadoras da sociedade internacional, como direito e diplomacia, Holsti denominou de "Cultura Diplomática Latino-Americana” própria da região, em virtude da herança legalista de suas antigas elites coloniais espanholas (Holsti, 1996; e Kacowicz, 2005, p. 10).

Assim, Kacowicz desconstrói um dos princípios basilares da concepção liberal moderna para a paz mundial, qual seja a necessidade primária de haver democracias consolidadas para que haja uma zona de paz, e este parece ser o caso da América do Sul. A partir de uma noção de estado forte, Holsti segue quase o mesmo roteiro discursivo da paz liberal democrática de Kacowicz. Para aquele, a paz permanente está ligada à presença de estados fortes, assim como para este, respectivamente (1998). Isso resultaria numa gradação em que se teriam níveis extremos: os estados fracos, dotados de baixa legitimidade vertical e horizontal, e no extremo oposto, os estados fortes. Assim, a fórmula para atingir estados fortes, paz estável e uma comunidade de segurança na região passaria pelo desenvolvimento dos estados em que proliferem as formas democráticas que, por sua vez, legitimariam os governos (Holsti, 2007).

Porém, Kacowicz, diferentemente de Holsti, percebe na paz sul-americana um processo de longo prazo, e não uma resultante eventual. A isso Kacowicz (2005) denomina de "Longa Paz Sul Americana", procurando as causalidades da mesma à existência de uma forte cultura legalista e conciliadora na região, mas também ao sucesso da consolidação dos estados nacionais depois de um primeiro momento pós-independência marcado por guerras de consolidação das fronteiras e das comunidades políticas independentes entre os países sul-americanos. Além disso, para a existência desta paz 
regional não apenas a tradição de resolução pacífica de controvérsias (convivência), mas também o fato de que havia desde o início da sociedade internacional sul-americana a norma do uti possidetis ita possideratu foi algo relevante.

Kacowicz reconhece que alguns elementos do realismo são oportunos para explicar a "longa paz sul-americana", porém vê um declínio desses elementos na região. O seu argumento frisa que a balança de poder como instituição da sociedade internacional vive dias de declínio na região após a abertura política democrática e o fim da Guerra Fria. Tais fatores contribuiriam para a estabilidade regional. Entre os maiores atores estatais sul-americanos, a exemplo do Brasil, Kacowicz reconhece sua hegemonia benigna na região, e o papel da política externa brasileira no estabelecimento das fronteiras com seus vizinhos usando meios pacíficos e legais, estimulando assim a resolução de disputas na região. Isso teria sido importante para atenuar as motivações geopolíticas para promover guerras de caráter revisionista (Kacowicz, 2005, p. 21).

Dentre dos elementos explicativos realistas de Kacowicz (1998, p. 38) também se reconheceu no caso sul-americano fatores como a distância geográfica, barreiras naturais topográficas e vegetativas, e desenvolvimento militar que priorizou a defesa ao meio exterior, em detrimento da defesa intra-regional, ou mesmo o desenvolvimento militar ofensivo. O autor, nesse sentido, aponta que uma Zona de Paz é mais facilmente mantida quando os Estados vizinhos estão isolados uns dos outros, pelos fatores acima mencionados, bem como pela distância que mantém de potências hegemônicas. Além disso, na América do Sul, Kacowicz (1998, p. 67) sugere haver um parâmetro fundamental: de forma geral, os Estados apresentam um "status satisfeito", pois não têm intenção expansionista militar na região, embora este autor também caia na armadilha teórica da dualidade político geográfica que estaria presente na América do Sul, e que tem sido própria de autores liberais como Domiguez (2007) e da própria Escola Inglesa como Hurrell (1998), os quais observam uma clara distinção entre a "Faixa Norte" (Northern Tier”) (Colômbia, Venezuela, Suriname e Guiana) e o Cone Sul (Argentina, Brasil, Chile, Peru, Bolívia, Paraguai, Uruguai e Equador).

Insiste-se, como também o fazem Hurrel (1998); Domínguez (2007) e Oelsner (2007; 2009) na narrativa dual e reforçada pelo argumento de que a região Andina apresenta maior potencial de instabilidade política, tanto sob o aspecto interno, quanto sob o ponto de vista internacional (Tulchin e Manaut \& Diamint, 2006).

Outra importante narrativa sobre a construção da paz na América Latina, e que faz sobreposição conceitual a Holsti e Kacowicz é a de Jorge Domínguez (2007), porém, este último autor parte de uma posição epistemológica liberal institucionalista. Dominguez sustenta os pressupostos dos analistas da Escola Inglesa, relatados anteriormente, segundo os quais a América Latina caminha para uma comunidade pluralista de segurança, principalmente os países do sul da América do Sul. Para este autor, a sub-região 
sul-americana possui algumas instituições e normas internacionais peculiares historicamente, e, entre elas, quatro são fundamentais: (i) a diplomacia, (ii) o direito internacional interamericano, (iii) o princípio da não-intervenção e (iv) a solução pacífica de conflitos.

Assim, Dominguez se une ao consenso bibliográfico que reconhece naquelas instituições as principais instituições internacionais da região sul-americana. $\mathrm{O}$ aspecto novo no argumento de Domínguez é que existe, para além delas, uma "prática de informalidade" quanto ao cumprimento das normas internacionais, com uma maior flexibilidade no trato da política internacional cotidiana, ao mesmo tempo em que faria com que as expectativas de cumprimento de uma norma não fossem totalmente seguras. (Domínguez, 2007).

Em segundo lugar, Domínguez destaca que, com a abertura política ocorrida entre os países centrais da América do Sul em meados da década de 1980, ocorreu uma consolidação progressiva da democracia como norma internacional. Adota, assim, uma perspectiva de paz democrática liberal, em que a adoção da democracia como norma internacional do Hemisfério Ocidental em geral, e da América Latina, em particular, teve um efeito transformador nas instituições sub-regionais. Se a democracia passa a ser desejável no continente, isso passou a significar que o regime político doméstico deixou de ser um assunto interno, e passou a ser uma questão também de direito internacional (Domínguez, 2007).

O princípio da não intervenção, uma das instituições mais sólidas e tradicionais da região, foi repensado do início da década de 1990. Assim como Holsti, Kacowicz e outros autores, Dominguez também repete o argumento dual segundo o qual a América do Sul não seria um continente homogêneo sob o ponto de visto da paz e das instituições internacionais. Uma comunidade pluralista de segurança somente existiria na região dos países que Domínguez (2007) denomina de “a parte sul da América do Sul”, que pode ser basicamente definida como o Cone Sul. Em tal sub-região, os principais requisitos de uma comunidade de segurança, como convergências de normas e integração transnacional se aprofundam a ponto de fazer com que não haja mais expectativa para solucionar os conflitos pela via da força. O argumento de Dominguez, para além do de Kacowicz e Holsti, concede, ao menos no âmbito das práticas institucionalistas da América do Sul, pouco espaço para o realismo: o sistema de equilíbrio de poder, para o autor, o qual teria sido fundado em 1860 na região, terminou nos anos 1990, e foi substituído por uma comunidade pluralista de segurança (de democracia, integração e princípios de direito internacional) (Domínguez, 2007, pp. 111-2).

Esse conjunto de discursos social-institucionalistas é tensionado quando contrastado com algumas ausências ontológicas daquelas narrativas. Assim como Holsti, Kacowicz entende que aspectos domésticos como instabilidade institucional, violência causada por crime organizado e gangues, bem como desigualdade econômica são aspectos centrais para a formação do quadro de segurança da região. No entanto, em todos esses 
autores (em Dominguez sequer é mencionada) essa dimensão da violência político-social doméstica, e os impactos que esses aspetos têm na reflexão teórica e em políticas voltadas para a América do Sul, é uma ausência analítica e empírica, e é, portanto, fortemente subdimensionada. O máximo que se considerou foi no sentido de apresentar essa dimensão como agendas de pesquisas que abram "possibilidades para discussão do fenômeno da violência e não só da ocorrência da guerra na região” (Kacowicz, 1998, p. 123).

Numa versão epistemológica construtivista, Buzan e Weaver (2003, p. 13) entendem a região como conjunto de práticas sociais que envolve as práticas da segurança, e é, portanto, socialmente construído, podendo coincidir ou não com outras práticas sociais, como o comércio, por exemplo. Ao questionarem o excepcionalismo da América do Sul como "anomalia conflitiva", Buzan e Weaver caminham na mesma direção de Holsti e Kacowicz, porém, ao contrário destes, questionam de maneira mais incisiva o paradoxo do porquê na América do Sul se observaram tão poucas guerras interestatais e, ao mesmo tempo, a região não avançou para uma comunidade de segurança (2003, p. 304). Como Holsti, Buzan e Weaver partilham do discurso dual sobre a presença de dois subcomplexos de segurança: a Região Andina e o Cone Sul, com dinâmicas e padrões distintos. No entanto, o que caracterizaria o primeiro subcomplexo de segurança, seria o impacto da produção e comércio ilegal de drogas na Colômbia, com influência norte-americana, ao mesmo tempo que no segundo o surgimento de uma comunidade de segurança via MERCOSUL; respectivamente. (idem).

Mas em que consiste a tensão específica que o trabalho de Buzan e Weaver introduz ao refletir sobre os complexos de segurança na América do Sul? Como se observou, os autores da Escola Inglesa que tem refletido o fenômeno do declínio de guerra na América do Sul apontam a tradição diplomática, o consenso em torno de alguns princípios como da não intervenção e uti possidetis iuris e existência de mecanismos de resolução pacífica de conflitos, porém, chama a atenção aspectos que esse discurso não explicita.

Tome-se o exemplo do discurso sobre o princípio de não intervenção, que é quase clausula pétrea em academias diplomáticas latino-americanas. Ao mesmo tempo em que, desde inicios do século XX, com o surgimento da doutrina Drago, armou-se uma barreira diplomática e conceitual a possibilidades de intervenção em assuntos internos de países latino-americanos, no entanto, em distintos momentos da história os mesmos países da região aceitaram, e os autores da Escola Inglesa, bem como os liberais institucionalistas, não perceberam que, seja direta ou indiretamente, a narrativa da não intervenção foi atenuada pelas diversas intervenções norte-americana em países da região. Assim, ao citarem David Mares, Buzan e Weaver acrescentam esse ponto crítico ou tensão contraditória: "Mares sarcasticamente considera esta uma divisão de trabalho: os latino-americanos defendem o princípio da não intervenção, enquanto os Estados Unidos praticam a intervenção” (2003, p. 317, tradução nossa). 
Ejustamente tem vindo da perspectiva realista-sociológica (ou neoclássica) de David Mares uma das fontes de tensões mais fortes à narrativa dos autores da Escola Inglesa e Liberal Institucionalista. David Mares reconhece que a América Latina, embora tenha tido avanços, permanece como uma região militarizada, com permanência de intenções hostis entre os atores, ou seja, o conflito, ou a possibilidade do uso da força ainda é uma ferramenta presente nas interações entre os atores, como se observa em Mares (2012, p. 600): "Devemos concluir que a militarização de conflitos é uma ferramenta de negociação entre estados em Comunidades Interestaduais em que o uso da força armada dentro da comunidade continua a ser um atributo soberano". No que se refere aos conflitos na América Latina, Mares reconhece que não há, por parte das potências locais, ações revisionistas ou intenções de expansionismo entre os atores, o que se assemelha ao conceito de "status satisfeito" apresentado por Kacowicz como conceito chave. Entretanto, reconhece haver conflitos de baixa intensidade, com periodicidade razoável na região: “... negociações militarizadas de baixo nível, tais como ameaças verbais e demonstrações de força, encontram, muitas vezes, o apoio popular e a reticência das organizações regionais em se envolver diretamente”. (Mares, 2012, p. 603).

Em contrapartida ao discurso celebratório da Escola Inglesa sobre a tradição da institucional, diplomática e normativa na América Latina, Mares afirma que tais instituições não teriam sido capazes de impedir, em alguns momentos, uma escalada de conflitos na região, bem como de impedir que os líderes militarizem suas discórdias ideológicas, quando estas são consideradas como essenciais à soberania nacional (2012, pp. 602-603). Isso posto, questões tradicionais como disputas territoriais e demarcações de fronteiras convivem com lutas ideológicas nas fronteiras, principalmente as que envolvem disputas por recursos naturais associados à pesca, exploração de petróleo, autonomias indígenas; e foram sobrepostas a questões ligadas ao tráfico de drogas, ao comércio ilícito de armas e contrabando, bem como a presença e disputas entre grupos ilegais geram ainda mais tensões às zonas fronteiriças da região (idem). Além disso, algo que não está presente nas obras dos autores da Escola Inglesa ou dos Liberais Institucionalistas são os grupos de atores não estatais violentos, como grupos criminosos, contrabandistas de armas e de pessoas e máfias, os quais tem exercido sensível impacto no desencadeamento de ações militarizadas por parte dos Estados sul-americanos. (idem)

Mares também contesta a eficácia da democracia e da integração econômica, valores tidos pelo institucionalismo liberal (Domínguez, 2007) ou mesmo por autores da Escola Inglesa (Hurrel, 1998; Olesner, 2007) como práticas fundamentais para a construção de uma comunidade de segurança (mesmo que parcial no Cone Sul). Democracia e integração seriam vetores fundamentais para se estabelecer uma zona de paz na região. No entanto, a estrutura institucional contemporânea, baseada em democracia e integração, proporciona apenas um fórum para conversação [barganha] diplomática entre as nações 
soberanas e democráticas e, assim, não se resolvem exatamente os problemas, o máximo que se atinge com isso é um acirramento das tensões entre os atores (2012, p. 610).

Por fim, ao fazer coro com Buzan e Weaver, para quem a concepção de segurança apresenta-se enquanto resultado da interação social entre os atores, para além das disposições materiais, Mares afirma (2012, p. 625): "Se as instituições regionais pudessem desenvolver um sentimento de identidade comum, isso poderia afetar as opiniões dos cidadãos sobre a legitimidade ou não do uso da força contra vizinhos”. E reforça, assim, sua perspectiva cética quanto à presença real de uma zona de paz na região, à luz da militarização e da utilização reiterada da ameaça ou uso real das Forças Armadas em situações de tensão na região.

Mesmo à luz de uma perspectiva analítica filiada à Escola Inglesa, um autor que busca tensionar narrativas da própria Escola é Federico Merke (2011). Embora destaque a existência "cinturão de direito internacional e diplomacia", ideia convergente com a narrativa de Kacowicz (2005), proveniente da herança latina e católica das antigas elites coloniais, tradicionalmente detentoras de sólida formação acadêmica e jurídica, e inclusive de uma consolidação na região de valores liberais como direitos humanos, democracia e economia de mercado na América do Sul; para Merke não se pode afirmar que haja uma comunidade de segurança na região, inclusive no Cone Sul, como pregado por Kacowicz (1998), Hurrel (1998), Holsti (1996), Domìnguez (2007), e Oelsner (2007, 2009).

Similar à crítica de David Mares, o fato de ainda existirem frequentes intervenções na América do Sul, mesmo que multilaterais, juntamente com a constante presença do governo americano (especialmente no Caribe), o nacionalismo, o estatismo e a presença de soberanias frágeis contribuem para que estágio solidarista ainda não tenha sido alcançado na região.

Para este autor, a despeito da estabilidade interestatal e do declínio da guerra como instituição primária na América do Sul, é necessário avaliar a qualidade da paz regional, bem como o perfil da sociedade transnacional. Este é a principal contribuição, e ao mesmo tempo a principal tensão introduzida por Merke, em relação às contribuições tradicionais (Escola Inglesa e Institucionalista). Em sua percepção, Merke resgata a dimensão social da violência transnacional. Para o autor, a América Latina em geral, e a América do Sul, em particular, é caraterizada pela de existência de um "lado escuro da sociedade civil”. Este lado seria composto por atores transnacionais que, atuando na ilegalidade, comprometem a qualidade da sociedade anárquica regional.

São várias dimensões sociais da sociedade civil que fazem com que Merke considere a América do Sul como apenas uma zona de paz negativa - porém, mais distante de uma comunidade de segurança de seus partners da Escola Inglesa: a violência social, que inclui organizações criminosas, de drogas, tráfico de armas e traficantes de pessoas, os quais Merke considera que tem se transformado num "real tensão para a sociedade civil regional" (Merke, 2011, p. 29). 
Na verdade, a ideia do lado escuro da sociedade internacional se inspira em trabalhos de Tickner et al (2011), quem observou o caso dos atores não estatais violentos na América do Sul, a partir do conflito colombiano e o tráfico de drogas, e enfatiza tal lado escuro da sociedade civil sul-americana a partir de uma perspectiva crítica. A análise de Tickner destaca a complexa relação de transações domésticas e internacionais que foi se constituindo entre os atores não estatais violentos com relação à cadeia do narcotráfico, o que constituiria o principal combustível para a permanência do negócio, em face dos programas estatais de erradicação, apreensão, entre outros. (Tickner et al, 2011, p. 414).

O elemento significativo de introduzir-se a dimensão social nas narrativas sobre paz permanente ou negativa nos leva a uma percepção dela comparada à ideia do mobius ribbon de segurança (Bigo, 2001), em que os pontos de segmentação territorial cedem lugar aos nexos de continuidade. Como anota Mônica Herz, numa perspectiva crítica:

Embora disputas territoriais tenham sido abundantes, houve poucos conflitos violentos entre Estados nas Américas desde o final do século XIX. [...] Atualmente, o tráfico de drogas e as atividades criminosas transnacionais, em geral, têm tornado mais aguda a ameaça para os Estados e indivíduos, e os problemas sociais e econômicos que caracterizam a região podem dar origem aos conflitos internacionais envolvendo as questões de recursos e processos de migração. A situação político-social doméstica em muitos países da América Latina pode gerar conflitos internos. As fragilidades dos mecanismos domésticos para a resolução de conflitos e o aparato estatal em geral têm gerado crises políticas ao longo da história das Américas (Herz, 2010, p. 111).

Da mesma forma, Héctor Saint-Pierre (2015, p. 17) numa perspectiva realista crítica introduz um novo ponto de tensão teórica bastante ausente nas análises de autores da perspectiva da Escola Inglesa e Liberal Institucionalista, e que está relacionada com a dimensão estatal, qual seja o papel das Forças Armadas. Qual é o papel destas num quadro de paz negativa? Saint-Pierre (2015, p. 17), primeiro, reflete sobre o papel do Estado, que deve garantir a eficácia das leis e das regras, bem como proteger e defender a sociedade contra aqueles que atentarem contra as regras. Saint-Pierre assim questiona e reflete sobre as diferentes utilizações das Forças Armadas na América Latina:

Apesar das diferenças apontadas, os conceitos do domínio da Defesa e da Segurança foram sofrendo mutações semânticas na América Latina que, em alguma medida, nós suspeitamos que obedecem a interesses políticos em todo o continente (2015, p. 18, tradução nossa)

Ao constatar que a indefinição semântica gera um espaço ambíguo, nebuloso e poroso para a ação política, Saint-Pierre observa a consequente utilização arbitrária e política das 
Forças Armadas na região. Ademais, ao se manter esta ambiguidade semântica, há um perigo adicional: o de colonização epistêmica, e em se tratando de segurança internacional e regional, tal aspecto tem efeitos políticos nocivos, e como se observa no debate até aqui explorado, gera impasses no avanço rumo à construção de uma zona de paz efetiva (2015, p. 19).

Para Saint-Pierre, líderes políticos e ministros da defesa da região sistematicamente foram incorporando novos temas e agendas, a partir de novos conceitos semânticos, o que acabou por aprofundar as ambiguidades e ambivalências na região e toma como exemplo a Declaração de Segurança das Américas, de 2003, em que se reconheceu uma "nova concepção da segurança no hemisfério de caráter multidimensional”. Com tal reconhecimento, tornaram-se indefinidos os limites normativos de regulação do emprego das Forças Armadas, deixando a cargo de cada governo como seria feito tal emprego, a partir de suas respectivas interpretações do novo conceito (2015, p. 19). Problemas decorrentes do tráfico de drogas e dos altos índices de violência, diante da fraqueza estatal, fizeram com que, segundo Saint Pierre, fossem atacados os sintomas e não as causas de tais problemas. Dessa forma, o emprego das Forças Armadas nas ruas produz uma percepção de segurança, diante do temor em que se encontra a sociedade, embora não se assista, de fato, a uma diminuição no narcotráfico ou mesmo nos índices de violência. A consequência é, portanto, uma maior debilidade estatal e democrática, com uma percepção errônea de fortalecimento das Forças Armadas e possíveis riscos à proteção aos Direitos Humanos e integridade física aos cidadãos (2015, p. 20).

Diante da incapacidade do Estado para conter o crime organizado e, até mesmo, a corrupção, Saint-Pierre aponta que o emprego das Forças Armadas parece ser uma "tentação irresistível" dos dias atuais, e alerta que este pode ser um caminho sem volta, em que se afasta do ideal democrático, e do emprego exclusivo das Forças Armadas para assuntos de Defesa. Vale aqui ressaltar que esta perigosa tendência à corrupção, em decorrência do reiterado uso indevido das Forças Armadas em questões domésticas, é um dos fatores chave para compreensão do nosso estudo de caso, qual seja o papel das Forças Armadas diante dos fluxos ilícitos em regiões de fronteira.

Em síntese, as diferentes narrativas e suas epistemologias não são lineares na compreensão da construção e caraterização da paz na América do Sul. Partindo dessa reflexão conceitual, a questão que se coloca é como se articulam empiricamente iniciativas de governança em segurança na região a partir de uma estrutura de paz negativa ou de paz híbrida? Quais as tensões, aproximações, contradições e insuficiências, que os frameworks epistémicos discutidos apresentam quando confrontados com uma realidade empírica.

\section{América do Sul: tensões das narrativas numa zona de paz negativa}

Partindo de desenvolvimentos empíricos em matéria de segurança e defesa, investimentos militares e percepções de indicadores usados por algumas ONGs internacionais 
que compilam dados sobre paz e violência, esta seção tem por objetivo apresentar e discutir como as narrativas conceituais apresentadas na primeira seção reproduzem consistentemente parte da realidade, mas principalmente como tais narrativas conceituais são por vezes rebatidas e confrontadas tanto por fatos, quanto por percepções que emergem da realidades empíricas.

\section{Congruências e incongruências narrativas nas práticas institucionais e nos investimentos militares}

Consistente com parte da literatura apresentada na seção anterior, uma das iniciativas recentes mais importantes no sentido de consolidar a Zona de Paz na região foi a criação, em 2008, da União das Nações Sul-Americanas (UNASUL), por meio de um Tratado Constitutivo ${ }^{3}$, e a principal instituição criada para lidar com temas que vão da defesa à segurança foi o Conselho de Defesa Sul-Americano (CDS) ${ }^{4}$, o primeiro a abarcar toda a América do Sul, e, por este motivo, diferente do Mercosul, da Comunidade Andina (CAN) e da OTCA amazônica. O objetivo principal do CDS é:

... implantar políticas de defesa em matéria de cooperação militar, ações humanitárias e operações de paz, indústria e tecnologia de Defesa, formação e capacitação. Objetivos: a) Consolidar uma zona de paz sul-americana; b) Construir una visão comum em matéria de defesa; c) Articular posições regionais em foros multilaterais sobre defesa; d) Cooperar regionalmente em matéria de defensa; e) Apoiar ações de destruição de minas, prevenção, mitigação e assistência a vítimas de desastres naturais. ${ }^{5}$ (tradução nossa)

Houve, portanto, desde o início uma vocação para lidar com problemas intrínsecos à região, tais como o tráfico de drogas, crime organizado, disputas militarizadas interestatais e altos índices de violência e homicídio, e isso foi objeto de institucionalização política na própria estrutura do CDS. Como chama a atenção Trujillo:

Com a Comunidade Sul-Americana de Nações, que logo se converteu naquilo que atualmente conhecemos como Unasul, e que em matéria de segurança [e defesa] dispõe de instrumentos como o Conselho de Defesa Sul-americano e o Conselho Sul-Americano em Matéria de Segurança Cidadã, Justiça e Coordenação de Ações contra a Delinquência Organizada Transnacional (Trujillo, 2014, p. 195, tradução nossa).

\footnotetext{
${ }^{3}$ Ver o Tratado Constitutivo da UNASUL. Disponível em: http://www.planalto.gov.br/ccivil_03/_Ato20112014/2012/Decreto/D7667.htm.

${ }^{4}$ Tratado Constitutivo da UNASUL. Disponível em: http://www.unasursg.org/es/node/21.

${ }^{5}$ Tratado Constitutivo da UNASUL. Disponível em: http://www.unasursg.org/es/node/21.
} 
No entanto, em paralelo a esses desenvolvimentos institucionais e normativos que parecem ir em direção dos apontamentos conceituais encaminhados pela Escola Inglesa e pelo Institucionalismo Liberal, observa-se alguma bibliografia, sobretudo de natureza realista, que tenciona o alcance dessas iniciativas. Marco Cepik (2010), por exemplo, tem argumentado que, a América do Sul observa ameaças internas persistentes relacionadas ao narcotráfico e à violência rural e urbana. Para o autor: "Países como Colômbia, Brasil e Venezuela têm taxas de criminalidade três vezes superiores à média mundial, além de níveis elevados de violência relacionados com a criminalidade urbana, acidentes automobilísticos, tráfico de drogas, conflitos sociais e o crime organizado" (Cepik, 2010, p. 63). De outro lado, o autor observa um processo gradual de erosão da legitimidade estatal, frente à intensificação da desigualdade social e subdesenvolvimento econômico.

Assim, a realidade política da região pode tensionar tanto o desenvolvimento histórico normativo-institucional quanto as teorias, se se observa a jovem história da UNASUL e o discurso celebratório da Escola Inglesa sobre a tradição institucional, diplomática e normativa na América Latina em alguns momentos, pois se sabe que não se pode evitar uma escalada de conflitos na região, bem como impedir que os líderes militarizem suas discórdias ideológicas, como previsto por David Mares (2012, pp. 602-603).

Um exemplo onde se nota a militarização foi o episódio em que, em 2008, pouco antes da criação da UNAUL, houve uma ofensiva da Colômbia em território equatoriano, na região de Putumayo, em que foi morto o porta-voz das FARC e segundo na hierarquia de comando, Raul Reyes. Embora tal episódio tenha sido resolvido de forma diplomática, houve um aumento das tensões nos países fronteiriços com a Colômbia, principalmente no que diz respeito ao transbordamento de atividades das Forças Armadas Revolucionárias da Colômbia (Farc) e de grupos paramilitares para os países da região, bem como a preocupação com a influência dos Estados Unidos no país colombiano. Certamente nenhumas das instituições existentes na América do Sul, nem mesmo a Organização dos Estados Americanos (OEA), especializadas em prevenção de conflitos, foram capazes de evitar uma escalada de conflito diplomático e de tensões militarizadas na ocasião.

Mas nem sempre o grupo de intelectuais que se apoiam na narrativa das instituições, normas e princípios para evidenciar a paz negativa na América do Sul se afasta de suas premissas da realidade. Em 2010, por exemplo, houve a deflagração de uma crise política na Bolívia em decorrência da violência causada pelos grupos detentores da exploração de gás que foram contra a nacionalização do recurso e pleiteavam a autonomia política e o não reconhecimento de Evo Morales como presidente. As províncias envolvidas foram Santa Cruz, Beni, Pando, Tarija e Sucre. O conflito gerou uma onda de protestos e violência no país, envolvendo a população indígena, as forças armadas e grupos "separatistas", bem como uma crise de abastecimento. O problema de base na Bolívia, e catalisador de violência, são as assimetrias sociais e má distribuição de riquezas no país, o que geram 
estruturas de profunda desigualdade que fez com que medidas propulsionadas pelo presidente Evo não fossem aceitas pelas camadas tradicionais da sociedade. Neste episódio, a UNASUL fez uma intervenção em apoio ao presidente boliviano e mostrou-se uma instituição capaz de mediar e resolver conflitos na região (Cepik, 2010, p. 65). Provavelmente essa uma das razões que levam a autores de perspectiva crítica, como Mônica Herz a fazer uma avaliação otimista, que tensiona com a de David Mares, sobre os mecanismos de confiança mútua existentes e resolução de conflitos na região, em face dos conflitos de baixa intensidade, ou mesmo em vista da presença de novas ameaças, e assim manter a emergência de dilemas de segurança na região sob controle, como se pode observar em:

... a existência de disputas de fronteira, a presença de problemas de segurança internos e transnacionais que poderiam gerar conflitos entre Estados, e as disputas por prestígio, poder e influência entre Estados estão presentes no mesmo cenário em que ocorre o avanço do processo de desenvolvimento da capacidade militar dos países latino-americanos. [...] Mas meu argumento é que as condições para o desenvolvimento de um paradoxo de segurança não estão amplamente presentes, pois a cultura da confiança tem se desenvolvido aqui, que promove a resolução pacífica das disputas (Herz, 2010, p. 113).

As análises baseadas na Escola Inglesa e no Institucionalismo Liberal também parecem identificar o impacto das normas e instituições ao longo do tempo na América do Sul de forma sistêmica, sem atentar para as partes dessas instituições e sem apontar para o fato de que elas exprimem ambivalências nos aspetos práticos e conceituais de segurança e defesa, e, por conseguinte, o quanto isso afeta a qualidade da paz sulamericana e o quanto contribui para retardar a mudança do estágio de paz negativa para paz permanente.

Um exemplo disso se refere à questionável divisão temática dos Conselhos dentro do CDS, pois em face da realidade sul-americana, torna-se difícil de observar mais nitidamente e na prática seu impacto funcional. e talvez isso derive da ambígua diferenciação entre segurança e defesa que é própria da região. Segurança, na clássica definição de Buzan e Waever (1998), é o estado em que estados e sociedades estão "livres de ameaças existências", enquanto a defesa refere-se a "administrar a força letal e se dissuadir inimigos que possam ameaçar a soberania nacional” (Saint-Pierre, 2015). Ou, a defesa refere-se aos meios e agências, principalmente as Forças Armadas de cada pais, com fins de garantir o estado existencial da segurança.

Ao se partir dessa definição, certa ambivalência se sobressai quando se atenta para a estrutura organizacional interna da UNASUL. Além do Conselho de Defesa Sul-Americano, uma instituição basicamente voltada para a defesa, há dois Conselhos que também lidam com temas relativos à segurança. Primeiramente, o Conselho Sul-americano 
em Matéria de Segurança Cidadã, Justiça e Coordenação de Ações contra a Delinquência Organizada Transnacional ${ }^{6}$, criado em 2012, e entre outros objetivos procura:

Fortalecer a segurança cidadã, a justiça e a coordenação de ações para enfrentar a Delinquência Organizada Transnacional [...] [e] impulsionar a cooperação judicial, policial e das agências de inteligência, e formular diretrizes em matéria de prevenção, reabilitação e reinserção social.

Por outro lado, foi criado um conselho para lidar com o principal problema da região: o problema das drogas, qual seja o Conselho Sul-americano de Luta Contra o Narcotráfico (CSLCN), criado em 2009, e tem como objetivo principal "um foro de consulta, coordenação e cooperação em matéria de prevenção e luta contra o problema mundial das drogas"

Dentre as narrativas sul-americanas, Hector Saint-Pierre (2013), um autor com filiação realista crítica, oferece instrumentos para entender os motivos políticos dessa diferenciação. Segundo este autor, de perspectiva realista crítica, há vários motivos para isso: a CSLCN obedece à clara intenção do CDS de separar a agenda de defesa da de segurança, não apenas por considerações conceituais, mas também por questões institucionais e operacionais (a representação institucional no CSLCN é constituída pelos ministros de governo e/ou do interior e entidades especializadas que manejam o tema de narcotráfico na região sul-americana). Em segundo lugar, Saint-Pierre destaca que o foco estritamente militar em questões de defesa - ou "defesa dura" - dado ao CDS tem fundamento: no fato de que isso evitaria que as Forças Armadas dos países da América do Sul sejam usadas para resolver problemas de segurança pública e assim possam se concentrar na defesa nacional (Saint-Pierre, 2013).

e em terceiro lugar, Saint-Pierre destaca que há uma clara intenção de se afastar da ambiguidade trazida pelo conceito de segurança multidimensional: “O bom de escrever sobre o conceito de "multidimensionalidade da segurança" no âmbito do CDS é que não há nada a dizer. Com efeito, nos documentos emitidos pelo CDS não se constata nenhuma linha dispensada a este conceito equívoco" (Saint-Pierre, 2013, p. 418). Conforme se notou na seção anterior, para Saint-Pierre, líderes políticos e ministros da defesa da região afirmam o caráter multidimensional da segurança no hemisfério tornando indefinidos os limites normativos de regulação do emprego das Forças Armadas, e deixando a cargo d. cada governo como seria feito tal emprego, a partir de suas respectivas interpretações do novo conceito (2015, p. 19).

\footnotetext{
${ }^{6}$ Conselho Sul-americano em Matéria de Segurança Cidadã, Justiça e Coordenação de Ações contra a Delinquência Organizada Transnacional. Disponível em: http://www.unasursg.org/es/node/23.

${ }^{7}$ Conselho sobre o Problema Mundial das Drogas em http://www.unasursg.org/es/node/30.
} 
Mas há também razões de ordem social que refletem no arcabouço institucional criado pela UNASUL que separa a segurança da defesa, e acabam gerando ambivalências que vão se refletir nas iniciativas de governança regional de segurança e defesa ao estilo da construída por aquela organização: Dangond adverte a este respeito:

\begin{abstract}
Realizar um debate sobre as drogas, no âmbito de uma realidade [social] violenta, cria dificuldades enormes para discriminar até onde as drogas e a violência [social] estão associadas estruturalmente e estão produzindo altos níveis de impacto (Dangond, 2014, p. 222, tradução nossa).
\end{abstract}

Esse sentido, esta divisão dos três Conselhos, em que segurança e defesa percorrem estradas de mão dupla, cada qual com seus objetivos principais e específicos, agendas e planos de ação, acabam por gerar desafios de ordem prática, tanto para prevenir conflitos, quanto para propor agendas de forma coordenada por parte dos países De fato, entende-se que tal divisão não é estanque, pois as questões que acometem a agenda de segurança da região não apenas de cunho militar estrito, ligadas ao plano de fundo de violência estrutural, tais como problemas ligados à produção e ao tráfico de drogas, são essencialmente transversais, e, além disso, podem ser locais, domésticos, nacionais, regionais ou transnacionais, ocasionando, por vezes, mobilização das Forças Armadas, seja no âmbito interno ou externo; e, ao mesmo tempo, trazer riscos à segurança cidadã (social), tal como fora apontado por Saint-Pierre (2015), e por outros autores, de diferentes epistemologias, discutidos na seção anterior (Merke, 2011; Tickner, 2011; Herz, 2011; Mares, 2011).

Na mesma linha de raciocínio, em que também não há uma clara diferenciação de políticas de segurança e defesa, a temática dos investimentos militares na América Latina mostra como as narrativas epistémicas sobre a paz negativa podem ser tensionadas. Embora a sustentação discursiva da Escola Inglesa (sul-americana) e até da epistemologia crítica sobre como mecanismos de prevenção de conflitos atenuam dilemas e paradoxos de segurança (Herz, 2010), os investimentos militares cíclicos na região apontam ainda para o surgimento de dilemas de segurança tradicionais entre países vizinhos. O Brasil, o Chile e a Venezuela, por exemplo, destacaram-se nas duas primeiras décadas dos anos 2000 enquanto principais compradores de armamentos da América Latina. e tais países adquiriram armamentos sofisticados como os aviões de combate americanos F-!6 por parte do Chile, os aviões russos Sukhoi -30 por parte da Venezuela, e os aviões suecos Gripen NG por parte do Brasil.

O que foi chamado de nova corrida armamentista do início deste milênio, está relacionado, acima de tudo, com a melhoria da posição política regional, e até global, de alguns países da região, especialmente nos casos do Brasil, do Chile e a da Venezuela (Villa e Weiffen, 2014). No entanto, tanto as impressões erradas de alguns países 
sobre as reais intenções dos compradores, quanto a falta de clareza destes com relação aos armamentos alimentam crenças de que o build-up armamentista tinha como metas objetivos militares tradicionais relacionados ao dilema de segurança.

A ideia mantida por autores que utilizam frameworks críticos, segundo a qual o desenvolvimento de um paradoxo de segurança não se encontra amplamente presente, pois a cultura da confiança tem se desenvolvido na região, e promoveria a resolução pacífica das disputas (Herz, 2010) ou mesmo da Escola Inglesa em que os dilemas de segurança predominariam basicamente no nível intra-estatal ou doméstico levanta a questão de porque a modernização armamentista na América do Sul continua a gerar representações que se assemelham com evidentes dilemas de segurança. O nosso argumento é que tais movimentos de corrida armamentista, sejam reais potenciais ou baseados em falsas percepções das motivações daqueles que se modernizam, representam um ponto crítico que reaparece de forma cíclica na América do Sul, colocando à prova teses relacionadas com a existência consistente da zona de paz democrática ou da comunidade de segurança.

Embora esse movimento cíclico não invalide completamente essas teses sobre a paz (negativa) ou sobre a eficácia das instituições de mediação de conflitos, acaba lhes faltando consistência analítica exatamente porque tais teses não questionam sob quais condições suas hipóteses são reforçadas e em quais há um efeito suspensivo dos dilemas ou paradoxos de segurança (Villa, 2008).

Em outras palavras, mesmo que se reconheça que América do Sul é uma região que se encontra cada vez mas distante de grandes guerras tradicionais (a última aconteceu nos anos 30 do século passado, a do Chaco ), o problema da incompreensão das motivações de estados sobre qualquer movimento de build-up armamentista gera momentos de tensão entre países vizinhos, o que, por sua vez, gera efeitos suspensivos nas normas e nos valores compartilhados que derivam de uma zona permanente de paz, apesar de que quase nunca se chegue ao extremo de romper aquelas normas e valores para iniciar os ciclos de conflitos previstos para um dilema de segurança.

Ou seja, o ponto crítico real, potencial ou produto de falsas percepções sobre intenções de atores num momento histórico em que se especula sobre a existência de uma corrida armamentista é um momento histórico que reaparece periodicamente, e que os pressupostos epistémicos, de qualquer filiação, de uma zona de paz sul-americana, ou comunidade de segurança, ainda não conseguem explicar de forma satisfatória (Villa, 2008).

Embora seja correto afirmar que a América do Sul tenha construído uma histórica zona de "longa paz" (Kacowicz, 1998), e se por isso se deve entender a ausência de guerras ou poucas guerras desde a formação do moderno sistema de estados sul-americanos, também é verdade que as análises baseadas na zona de paz sul-americana ou em comunidades de segurança têm prestado pouca atenção para o problemas derivados de escassez de informação no processo de buil-up armamentista sul-americano, o que 
tem por consequência o incremento de temores sobre intenções, capacidades e ações projetadas sobre atores estatais, a cada momento que o tema da corrida armamentista reaparece. Nos últimos 30 anos, quando o build-up reaparece, seja qual for os atores deste, temores sobre o impacto na segurança reaparecem, o que de alguma maneira expõe a precariedade das Confidence-Building Measures (CBMs), principal ferramenta dos regimes de segurança na América Sul, através dos quais é possível, aproveitar "acurada informação para acalmar falsos boatos" (Lindle, 2007, p. 1).

Com a modernização armamentista ocorrida na América do Sul, a primeira misrepresentation é gerada a partir de atores que estão em ambos subsistemas de segurança, principalmente países vizinhos do Chile e da Venezuela, o que acaba gerando uma dinâmica de segurança transversal em ambos os sistemas, e reforça a unidade empírica e analítica do complexo regional de segurança sul-americano, para o qual as duas análises prestam pouca atenção.

Também é importante destacar que, dado que os três atores estatais fonte dessas falsas representações (Brasil, Chile e Venezuela) localizam-se por toda a região sulamericana (ou seja, em ambos os sub-sistemas de segurança, Cone sul e região andina) questiona-se a fragmentação teórica dualista característica da Escola Inglesa, Liberal Institucionalista e construtivista (Holsti, 1996; Hurrell, 1998; Kacowicz, 2005; Domínguez, 2007; Oelsner, 2007) que analisamos na seção 2, e que visualizam um subsistema de segurança mais tradicional nos países andinos, e uma comunidade de segurança no Cone Sul. Não faz sentido em se falar em dois subsistemas de segurança como sustentam as teorias dualistas (um tradicional, de comportamentos militarizados nos países andinos e outro perto de uma comunidade de segurança no Cone Sul), já que ambos são perpassados por comportamentos tradicionais que levam a dilemas de segurança tradicionais, mesmo que esses dilemas estejam no campo das representações sobre as intenções.

Nesse sentido, a dramatização realista sobre a existência de uma corrida armamentista na América do Sul em alguns momentos históricos é importante porque identifica e reconhece certas dificuldades, imagens e desconfianças entre estados sul-americanos decorrentes do ciclo de upgrade e modernização do parque militar contemporâneo.

Finalmente, embora reconheça-se e coincida-se com o argumento de diferentes perspectivas epistemológicas (como as referidas acima) de que a inexistência de grandes atores territoriais expansionistas foi uma importante condição para o declínio da guerra como instituição primária entre estados sul-americanos, isso não anula contradições que teoricamente não poderiam ser consistentemente bem explicadas quando se trata de analisar a conduta de grandes atores na região.

Pois se como prevê a teoria Liberal Institucionalista, normas e regimes ajudam a limitar condutas que estimulem a deserção (o não cumprimento da norma) então a modernização brasileira, chilena e venezuelana do início deste século podem ser 
interpretadas pelos países da América do Sul como se o Brasil estivesse na direção oposta ao artigo 3 do Conselho de Defesa Sul-americano, que trata justamente do objetivo dos países membros de reduzir as assimetrias nos sistemas de defesa na América do Sul. De acordo com o índice Ranking do Poder Militar na América do Sul o poderio militar brasileiro é maior do que países como Colômbia e Chile em quase em 45\%; e em relação ao Peru, Venezuela e Argentina é em torno de 51\% 53\% e 55\%, respectivamente, e, por fim, em relação ao Equador, é maior em 78\% (Military Power Review, 2014). O questionamento, que é também um questionamento da epistemologia Liberal Institucionalista, é como se explica esta contradição entre o que está prescrito pelo artigo 3 do CDS e o aumento real das assimetrias de poder? Leve-se em conta que o aumento dessas assimetrias acontecem de forma contemporânea à criação do CDS.

\section{As pressões epistêmicas derivadas dos índices internacionais sobre as narrativas de paz sul-americana}

As narrativas da Escola Inglesa e Liberal Institucionalista, e inclusive das perspectivas críticas, também são pressionadas quando leva-se em conta a percepção de que a América do Sul tem sido retratada por organizações não governamentais de amplo alcance, as quais constroem indexadores gerais ligados ao desenvolvimento, por meio dos quais é possível averiguar o "estado da arte" de determinado país ou região, para determinado tópico, como corrupção ou fragilidade estatal, bem como determinar se houve, ao longo do tempo, em algum progresso ou regresso específico.

Entende-se que não se deve tornar tais dados fonte inequívoca de interpretação e classificação da realidade observada, mas sim buscar uma primeira argumentação lógico-causal do que se deseja argumentar: qual seja o contexto de violência doméstica, que, muitas vezes, se torna transnacional, e que impede a formação de uma zona de paz positiva consolidada na região. Ressalve-se também que tais índices, na maioria das vezes, estão embutidos de percepções normativas sobre como construir uma paz liberal em estados que são percebidos como fracos.

Um destes índices é o Corruption Perception Index (CPI), publicado anualmente, desde 1995, pela Organização Não-Governamental International Transparency, classifica países e territórios com base no grau de corrupção do setor público percebida por experts políticos e empresários de determinada localidade. $O$ índice também utiliza como fonte uma série de publicações e indicadores de renomadas instituições internacionais, tais como: Asian Development Bank, World Bank, African Development Bank, World Economic Forum, entre outras. Apesar do escopo limitado, já que tende a capturar percepções, o índice é atualmente uma eminente fonte de mapeamento do nível de corrupção no mundo ${ }^{8}$.

\footnotetext{
${ }^{8}$ Para maiores informações, consultar: http://www.transparency.org/research/cpi/.
} 
Os principais indicadores do índice são (i) a pontuação e (ii) a posição ocupada pelo país/território em termos do grau de corrupção percebida. A pontuação variou de o (mais corrupto) a 10 (menos corrupto), até o ano de 2011, sendo que a partir de 2012 a escala passou a ser de o (mais corrupto) a 100 (menos corrupto). A posição de um país/território no ranking reflete o seu grau de corrupção, sendo que o primeiro colocado no ranking é o país com o menor nível de corrupção percebida do mundo. Em 2014, o ranking de países foi liderado pela Dinamarca, seguida de Nova Zelândia, Finlândia, Suécia e Noruega.

Em linhas gerais, os países da América do Sul, com exceção ao Chile e, em certa medida, ao Uruguai, historicamente apresentam um desempenho ruim em termos de percepção da corrupção de acordo com o CPI. Como é possível observar na Tabela 1, a seguir, praticamente todos os países da região decaíram na classificação do CPI desde os anos 2000, com destaque acentuado para Argentina, Paraguai e Venezuela.

\section{Tabela 1 - Posição dos países da América do Sul no Ranking do Corruption Perception Index (CPI).}

\begin{tabular}{|c|c|c|c|c|c|c|c|c|c|c|c|c|c|c|c|}
\hline País/Ano & 옹 & 옹 & ్ㅗㅇ & m. & ষ্ণ & 옹 & : & 옹 & 曲 & 옹 & 웅 & 검 & స్ & M & 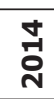 \\
\hline Argentina & 52 & 57 & 70 & 92 & 108 & 97 & 93 & 105 & 109 & 106 & 105 & 100 & 102 & 106 & 107 \\
\hline Bolivia & 71 & 84 & 89 & 106 & 122 & 117 & 105 & 105 & 102 & 120 & 110 & 118 & 105 & 106 & 103 \\
\hline Brazil & 49 & 46 & 45 & 54 & 59 & 62 & 70 & 72 & 80 & 75 & 69 & 73 & 69 & 72 & 69 \\
\hline Chile & 18 & 18 & 17 & 20 & 20 & 21 & 20 & 22 & 23 & 25 & 21 & 22 & 20 & 22 & 21 \\
\hline Colombia & 60 & 50 & 57 & 59 & 60 & 55 & 59 & 68 & 70 & 75 & 78 & 80 & 94 & 94 & 94 \\
\hline Ecuador & 74 & 79 & 89 & 113 & 112 & 117 & 138 & 150 & 151 & 146 & 127 & 120 & 118 & 102 & 110 \\
\hline Guyana & - & - & - & - & - & 117 & 121 & 123 & 126 & 126 & 116 & 134 & 133 & 136 & 124 \\
\hline Paraguay & - & - & 98 & 129 & 140 & 144 & 111 & 138 & 138 & 154 & 146 & 154 & 150 & 150 & 150 \\
\hline Peru & 41 & 44 & 45 & 59 & 67 & 65 & 70 & 72 & 72 & 75 & 78 & 80 & 83 & 83 & 85 \\
\hline Suriname & - & - & - & - & 49 & 78 & 90 & 72 & 72 & 75 & & 100 & 88 & 94 & 100 \\
\hline Uruguay & - & 35 & 32 & 33 & 28 & 32 & 28 & 25 & 23 & 25 & 24 & 25 & 20 & 19 & 21 \\
\hline Venezuela & 71 & 69 & 81 & 100 & 114 & 130 & 138 & 162 & 158 & 162 & 164 & 172 & 165 & 160 & 161 \\
\hline
\end{tabular}

Fonte: Elaborado pelos autores com base nas publicações Corruption Perception Index (CPI)

Com relação à pontuação dos países da região entre os anos 2000 e 2011 (último ano da antiga metodologia com escala de o/mais corrupto a 10/menos corrupto), a média da região girou em torno dos 3,5 pontos. Se retirarmos do cálculo Uruguai e Chile, países que mantiveram uma média no período entre 6 e 7 pontos, a média da região cai para algo em torno de 2,9 pontos. O destaque negativo fica por conta da Venezuela, Paraguai e Equador, todos com média abaixo dos 2,5 pontos. 
Tabela 2 - Pontuação dos países da América do Sul no Corruption Perception Index (CPI).

\begin{tabular}{|c|c|c|c|c|c|c|c|c|c|c|c|c|c|c|c|}
\hline País/Ano & ๕ั & ర్ & ్ㅗํ & ֻั & ষ্ণ & 옹 & ๕ั & ồ & : & 올 & 옹 & ন্- & 궁 & m. & ث্ \\
\hline Argentin & 3,5 & 3,5 & 2,8 & 2,5 & 2,5 & 2,8 & 2,9 & 2,9 & 2,9 & 2,9 & 2,9 & 3,0 & 35 & 34 & 34 \\
\hline Bolivia & 2,7 & 2,0 & 2,2 & 2,3 & 2,2 & 2,5 & 2,7 & 2,9 & 3,0 & 2,7 & 2,8 & 2,8 & 34 & 34 & 35 \\
\hline Brazil & 3,9 & 4,0 & 4,0 & 3,9 & 3,9 & 3,7 & 3,3 & 3,5 & 3,5 & 3,7 & 3,7 & 3,8 & 43 & 42 & 43 \\
\hline Chile & 7,4 & 7,5 & 7,5 & 7,4 & 7,4 & 7,3 & 7,3 & 7,0 & 6,9 & 6,7 & 7,2 & 7,2 & 72 & 71 & 73 \\
\hline Colombia & 3,2 & 3,8 & 3,6 & 3,7 & 3,8 & 4,0 & 3,9 & 3,8 & 3,8 & 3,7 & 3,5 & 3,4 & 36 & 36 & 37 \\
\hline Ecuador & 2,6 & 2,3 & 2,2 & 2,2 & 2,4 & 2,5 & 2,3 & 2,1 & 2,0 & 2,2 & 2,5 & 2,7 & 32 & 35 & 33 \\
\hline Guyana & - & . & - & 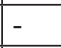 & - & 2,5 & 2,5 & 2,6 & 2,6 & 2,6 & 2,7 & 2,5 & 28 & 27 & 30 \\
\hline Paraguay & - & 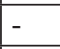 & 1,7 & 1,6 & 1,9 & 2,1 & 2,6 & 2,4 & 2,4 & 2,1 & 2,2 & 2,2 & 25 & 24 & 24 \\
\hline Peru & 4,4 & 4,1 & 4,0 & 3,7 & 3,5 & 3,5 & 3,3 & 3,5 & 3,6 & 3,7 & 3,5 & 3,4 & 38 & 38 & 38 \\
\hline Suriname & - & - & - & - & 4,3 & 3,2 & 3,0 & 3,5 & 3,6 & 3,7 & & 3,0 & 37 & 36 & 36 \\
\hline Uruguay & - & 5,1 & 5,1 & 5,5 & 6,2 & 5,9 & 6,4 & 6,7 & 6,9 & 6,7 & 6,9 & 7,0 & 72 & 73 & 73 \\
\hline Venezuela & 2,7 & 2,8 & 2,5 & 2,4 & 2,3 & 2,3 & 2,3 & 2,0 & 1,9 & 1,9 & 2,0 & 1,9 & 19 & 20 & 19 \\
\hline
\end{tabular}

Fonte: Elaborado pelos autores com base nas publicações Corruption Perception Index (CPI)

Os dados referentes ao Relatório de $2014^{9}$, por exemplo, mostram que a Venezuela ocupou a $161^{\circ}$ posição, de um total de 175 países analisados, ou seja, quase o último lugar no mundo. Entre outros indicadores, o relatório se baseia na transparência orçamentária, liberdade de imprensa, independência judicial e competitividade. A maioria dos venezuelanos entrevistados definiu que os esforços do país para o combate à corrupção são ineficientes, perceberam um aumento geral da corrupção, e consideram a polícia a instituição mais corrupta do país.

A Colômbia, por sua vez, ocupou o $94^{\circ}$ lugar no ranking, entre 175 países investigados e, em consonância com o que se observou na Venezuela, a maioria das pessoas consideram as medidas do Estado para combater a corrupção ineficazes e consideram que a corrupção aumentou no país. Interessante, nesse sentido, observar que as instituições públicas consideradas as mais corruptas no país são os partidos políticos e as casas parlamentares. Vale notar que no relatório da Transparência Internacional de 2008, a Colômbia ocupava a $70^{\circ}$ posição e a Venezuela o $158^{\circ}$ lugar, e, sendo que ambos pioraram em seus índices, mas a piora da Colômbia foi proporcionalmente maior.

Os resultados trazidos pelo Corruption Perception Index mostram várias questões a serem ponderadas: as visões sobre a paz na América do Sul poderiam ser explicadas como uma dinâmica intrínseca ao sistema. Uma boa parte dos autores analisados na segunda seção deste artigo trabalha com a noção de estado forte versus fraco (Holsti,

${ }^{9}$ Disponível em: http://www.transparency.org/whoweare/organisation. 
1996; Kacowicz, 1998; Buzan e Weaver, 2003), e sobre os meios normativos para se atingir esse estágio de estado forte (que em geral são os meios da paz liberal).

Assim, há pouca diferenciação normativa entre as narrativas de algumas das escolas de pensamentos analisadas, especialmente as da Escola Inglesa e Liberal Institucionalistas, e as narrativas (numéricas, mas capazes de produzir e induzir representações), como aquelas produzidas pelo Corruption Perception Index. Quais são os critérios explicitados por autores da Escola Inglesa, por exemplo, para definir um estado forte? A corrupção acaba sendo um problema interno, com impactos transnacionais, como acaba mostrando o caso das empresas brasileiras multinacionais, caso exemplar disso e a mais "forte" de todas elas, a Odebrecht, acusada de corromper funcionários de vários governos sul-americanos para ganhar licitações de obras de infraestrutura na região, inclusive entre estados bem qualificados no index, caso do Uruguai.

A corrupção, que tem por origem nas causas que vão desde as heranças coloniais até a formação de uma cultura de estado patrimonial, em que o público e o privado tem pouca diferenciação, acaba minando as bases da paz dentro do estado mas ela tem também impacto na qualidade da "sociedade anárquica", como o caso Odebrecht mostra. As narrativas tradicionais (agrupadas sob a forma de epistemologias) não desconhecem o impacto de causalidades históricas na formação das relações entre estado e sociedade, por exemplo o impacto da herança colonial na América Latina em algumas instituições, mas quando o fazem, isso acontece de uma maneira celebratória (destacando, por exemplo, como isso ajudou a gerar formas relativamente bem consolidadas de uma cultura de paz estatal), mas a análise dessa mesmas tradições históricas sobre as formas de existir do doméstico profundo (relações entre estado e sociedade) tem referências e desenvolvimentos conceituais demasiado genéricas.

Nesse sentido, não é nenhuma novidade chamar a atenção para o fenômeno da interpenetração, ou interdependência de fatores domésticos (instituições, impacto das ideologias, políticas públicas, violência interna, entre outros) e de fatores internacionais, o que acaba por falhar em eficácia analítica a anacrônica premissa realista da separação, ou relativa autonomia entre os níveis internos e externos. Certamente autores como Holsti, Kacowicz, Buzan e Weaver, David Mares e Merke, em diferente medida, tem destacado, embora tenham produzido poucos trabalhos empíricos ao respeito, como aspectos domésticos relacionados com instabilidade institucional, violência causada por crime organizado e gangues, bem como desigualdade econômica são aspectos centrais para a formação do quadro de paz e segurança na região sul-americana, uma exceção a este respeito é o trabalho de Tickner et al (2011).

Se se enxerga com atenção, uma boa parte dos atritos diplomáticos que a Colômbia tem tido nos últimos anos com seus vizinhos, especialmente com o Equador e a Venezuela, foram consequência da catarse conflitiva doméstica e as pressões que esta 
gerou sobre as fronteiras geradas pelo conflito interno colombiano, com pressões de grupos guerrilheiros e narcotraficantes nas fronteiras, migrações para países vizinhos com origem no deslocamento de pessoas de origem colombiana, interpenetração de fronteiras tanto de quadrilhas criminosas, guerrilhas e forças armadas (a já aqui citada intervenção militar no Equador em 2008), prática intensa de contrabando de armas e os corredores para o comércio ilegal de drogas, entre outros.

Na prática, esses fatores domésticos acabam afetando a paz regional, e fazendo com que a América do Sul não mude do status quo de paz negativa para paz permanente ou comunidade de segurança. Como sustenta Didier Bigo (2001) a transnacionalização da segurança nos leva a uma percepção dela comparada à ideia do mobius ribbon de segurança, em que os pontos de segmentação cedem lugar aos nexos de continuidade. Dito de outra forma, os níveis estruturais (os agentes externos) e os níveis domésticos podem ser reforçar na geração de imagens securitizadas, o que acaba afetando a qualidade da paz possível.

Outro importante indicador de fragilidade estatal é elaborado pela Fund For Peace, organização que trabalha com foco na prevenção da violência e do conflito, por meio da promoção de uma segurança sustentável. A organização publica anualmente o seu Fragile States Index, elaborado com base em 12 indicadores dispostos em três grandes macro-áreas, quais sejam: (i) social - pressões demográficas associadas a desastres e doenças; presença de refugiados e/ou deslocados internos; violência entre grupos internos e migração de capital humano/fuga de "cérebros; (ii) econômica- desigualdade social, pobreza e declínio econômico; e , por fim, (iii) política e militar-legitimidade do Estado; serviços públicos, direitos humanos, aparato de segurança, fragmentação e disputa de poder por parte das elites ${ }^{10}$. Quanto menor a posição do país no ranking, maior é o nível de alerta em relação à fragilidade do Estado.

Esse tipo de índice reforça os achados conceituais de uma visão dual, ou de existência de dois sub-complexos de segurança diferenciados: um que avança para uma comunidade de segurança, mesmo numa situação de paz negativa localizado no Cone Sul, e outro, de natureza mais tradicional (com situações de paz híbrida, em que tensões militarizadas, violência de atores não estatais violentos e forte comércio ilegal de drogas e armas convive com a paz negativa, de baixa guerra interestatal.

Em 2015, foram analisados 178 países, sendo que a liderança do Index ficou por conta do Sudão do Sul, seguido de Somália, República Centro Africana e Sudão. Em linhas gerais, os países da América do Sul evoluíram ao longo da última década, com destaque para Brasil, Argentina, Chile e Uruguai (todos países do Cone Sul). Todavia, é possível

\footnotetext{
${ }^{10}$ Para maiores informações sobre a metodologia utilizada pelo Fund For Peace na elaboração do Fragile States Index, consultar http://fsi.fundforpeace.org/indicators
} 
perceber que Bolívia, Colômbia e Venezuela (todos países andinos) ainda estão na faixa dos 75 países com maior fragilidade social/econômica e política, de acordo com a publicação da Fund for Peace. Interessante destacar que no Ranking de 2012, por exemplo, a Venezuela foi colocada na $82^{\circ}$ posição e a Colômbia no $52^{\circ}$ lugar, de um total de 177 países, sendo caracterizados como "High Warninig" e "Very High Warning", respectivamente. O índice levou em conta, entre outros fatores, a presença de conflitos internos, de refugiados, pressão demográfica, pobreza, legitimidade estatal, aparatos de segurança do Estado e presença de assistência internacional.

\section{Tabela 3 - Posição dos países da América do Sul no Ranking do Fragile States Index (2015)}

\begin{tabular}{|l|l|l|l|l|l|l|l|l|l|l|l|}
\hline País/Ano & $\mathbf{2 0 0 5}$ & $\mathbf{2 0 0 6}$ & $\mathbf{2 0 0 7}$ & $\mathbf{2 0 0 8}$ & $\mathbf{2 0 0 9}$ & $\mathbf{2 0 1 0}$ & $\mathbf{2 0 1 1}$ & $\mathbf{2 0 1 2}$ & $\mathbf{2 0 1 3}$ & $\mathbf{2 0 1 4}$ & $\mathbf{2 0 1 5}$ \\
\hline Argentina & - & 122 & 149 & 151 & 148 & 148 & 145 & 145 & 144 & 144 & 141 \\
\hline Bolivia & - & 56 & 59 & 55 & 51 & 53 & 59 & 62 & 67 & 70 & 77 \\
\hline Brazil & 62 & 101 & 116 & 117 & 113 & 119 & 123 & 123 & 126 & 125 & 123 \\
\hline Chile & - & 132 & 158 & 157 & 155 & 155 & 153 & 151 & 152 & 153 & 150 \\
\hline Colombia & 14 & 27 & 33 & 37 & 41 & 46 & 44 & 52 & 57 & 59 & 61 \\
\hline Ecuador & 46 & 63 & 72 & 68 & 69 & 69 & 62 & 0 & 74 & 79 & 85 \\
\hline Guyana & - & - & 98 & 105 & 104 & 102 & 99 & 104 & 107 & 106 & 107 \\
\hline Paraguay & 36 & 87 & 100 & 104 & 106 & 106 & 100 & 107 & 104 & 102 & 103 \\
\hline Peru & 40 & 68 & 84 & 81 & 92 & 92 & 98 & 99 & 103 & 97 & 98 \\
\hline Suriname & - & - & 95 & 101 & 103 & 105 & 105 & 105 & 106 & 109 & 109 \\
\hline Uruguay & - & 120 & 150 & 151 & 154 & 153 & 153 & 154 & 155 & 155 & 155 \\
\hline Venezuela & 21 & 63 & 73 & 79 & 77 & 82 & 80 & 82 & 89 & 83 & 75 \\
\hline
\end{tabular}

Fonte: Elaborado pelos autores com base nas publicações Fragile States Index (Fund For Peace)

Ao observamos de maneira desagregada os indicadores de Colômbia e Venezuela, é possível perceber a evolução dos principais pontos de atenção de cada um dos países, de acordo com o Index. No caso da Colômbia, destacam-se a presença de refugiados e deslocados internos bem como a violência entre distintos grupos. Na Venezuela, por sua vez, o Index destaca problemas relacionados a itens como direitos humanos, legitimidade do Estado e a disputa de poder por parte das elites, todos com pontuação ascendente (piora) a partir de 2006.

Esses dados do índice revelam uma outra tensão teórica na conceptualização da Escola Inglesa de Kacowicz, inserida na sua dicotomia estado forte-estado versus fraco no chamado Terceiro Mundo, como chamamos a atenção na seção 2, segundo a qual seria comum países com fragilidades internas criarem uma relação não conflitiva com outros Estados, e, nesses casos, o dilema da segurança, adquiriria um arranjo doméstico peculiar:

O Dilema da Segurança confrontado pelo o Estado Frágil do Terceiro Mundo tende a ser principalmente doméstico: assim a percepção de insegurança advém, em 
primeiro lugar, de dentro de suas fronteiras, e não do exterior (Kacowicz, 1998, p. 14, tradução nossa).

Trata-se de um argumento importante apresentado por Kacowicz, embora não caracterize bem como opera esse dilema de segurança interno, quem são os atores, bem como os dilemas de motivação e ação com os quais esses atores domésticos precisam lidar. $\mathrm{O}$ argumento faz muito sentido porque ao chamar a atenção para a existência de dilemas de segurança internos, e novamente a causalidade mais visível para esse dilema de segurança interno tem que ser colocada no estado (fraco) com suas ausências sociais, sua incapacidade para produzir políticas públicas massivas, e em alguns casos, violência contra os direitos humanos e a fragmentação da autoridade.

Outro importante indicador que mostra a deterioração da capacidade estatal na produção de políticas públicas, e que reforça a ideia da existência de um dilema de segurança interno, desta vez pelo lado das limitações do estado para produzir políticas consistentes de segurança pública, é mostrada pelo Ranking "Las 5 o Ciudades Más Violentas del Mundo" (violência essa medida pelo número de homicídios sobre 100 mil habitantes), elaborado pela ONG mexicana Seguridad, Justicia y Paz. Na edição de 2015, das 50 cidades do Ranking, 21 estão localizadas no Brasil, 8 na Venezuela, 5 no México, 4 na África do Sul, 4 nos Estados Unidos, 3 na Colômbia e duas em Honduras. El Salvador, Guatemala e Jamaica participam do Ranking com uma cidade cada. A grande maioria, todavia, das 50 cidades mais violentas do mundo estão localizadas na América Latina (41 localizações) ${ }^{11}$.

Essa deterioração das condições da segurança pública entre países latino-americanos, mostra o que Merke (2011), na seção 2 deste artigo, chamou de o "lado escuro" da sociedade civil sul-americana, expresso na ação dos atores da violência social e reforçada quando se atenta para a ação de grupos violentos não-estatais ilegais que desenvolvem atividades como lavagem de dinheiro, tráfico de armas, tráfico de pessoas, extorsão, crime comum e político.

Dessa forma, ao se deslocar das teorias mainstream ${ }^{12}$, é possível projetar os holofotes conceituais para o ambiente deteriorado, que carece de presença mais ampla do Estado de bem-estar, o que acaba sendo um cenário em que se criam condições, e diminuem os custos, para a prática de crimes. Como sustentam Kelling e Coles, respostas militaristas e punitivas aos problemas domésticos sociais, quando isoladas, não trazem modificações mais profundas no ambiente, para que este não se torne celeiro de práticas criminosas, ou para que os criminosos não se tornem "heróis" para os adolescentes locais: ${ }^{13}$

\footnotetext{
${ }^{11}$ Para maiores informações, consultar http://www.seguridadjusticiaypaz.org.mx/sala-de-prensa/1356-caracas -venezuela-la-ciudad-mas-violenta-del-mundo-del-2015

${ }_{12}$ Como a teoria da Escola Inglesa, Realismo e o Liberal Institucionalismo.

${ }^{13}$ No original: Hard core predators and gang members wreak havoc with other youths, especially in poor and ghetto neighborhood. Education suffers and jobs flee the neighborhood both making a tough situation worse for inner city youth.
} 
Grandes predadores e membros de gangues provocam estragos junto a outros jovens, especialmente em bairros e guetos pobres. A educação é afetada e os empregos desaparecem do bairro, tornando a situação ainda pior para a juventude do interior. (Kelling e Coles, 1996, p. 247).

A mesma linha de argumentação é apresentada por Tokatlian quando ao referirse a Colômbia, de inicio deste século, observava que uma características do estado colombiano era a de um estado fracassado e incapaz de manter sua sociedade sob sua proteção e integridade e afirmou que à Colômbia caberia transitar entre o status de "Estado-fantasma" que, segundo o autor se refere a um Estado presente apenas em algumas zonas e ausente em outras; e "Estado-anêmico" onde todas suas forças são canalizadas para o combate dos distintos VNSAs (sigla em inglês para violent non state actors) (Tokatlian, 2002, p. 132).

Esses dados e abordagens que mostram a incapacidade do Estado de produzir políticas públicas de segurança pública são relevantes porque eles mostram que as teorias tradicionais que refletem a formação de paz na América do Sul tem feito uma enorme contribuição para explicar as causas da decadência da guerra na América do Sul. Assim, se levamos em conta a Escola Inglesa, seus autores fizeram uma leitura ipsis litteris da sociedade internacional sul-americana, ou seja, enquanto uma sociedade de estados. Nisso deram uma excelente contribuição ao reconstruir, sob uma perspectiva de sociologia histórica, a formação da região como uma zona de paz.

Por outro lado, a sua maior contribuição, pode ser também seu maior calcanhar de Aquiles teórico pelo que evidencia e em seguida excluiu. e o que se exclui é uma reflexão sobre a violência social e seu impacto perante a formação do Estado forte e sobre o efeito transnacional da violência de grupos não estatais violentos, realidade essa que acaba afetando, por fim, a qualidade da sociedade anárquica sul-americana.

\section{Considerações finais}

Percebe-se que as reflexões aqui analisadas, ora mais otimistas, ora mais pessimistas quanto à possibilidade de consolidação e aprofundamento da Zona de Paz na América do Sul, parecem concordar que os aspectos domésticos, tais como: estados fracos, estados fortes com regiões e situações de fragilidade, instituições democráticas instáveis, subdesenvolvimento e tensões sociais são elementos chave para a compreensão do quadro de segurança regional da América do Sul. Ademais, questões não tradicionais, como o tráfico de drogas, armas e contrabando são as ameaças mais presentes na região, bem como se notou, nos últimos anos, sobretudo a partir dos anos 2000, uma militarização da região com uso ambíguo das Forças Armadas e da utilização semântica de vocabulários na região, o que por si dificulta o avanço para uma Comunidade 
Pluralista de Segurança. Como isso pressiona narrativas sobre a formação de uma zona de paz (negativa) na América do Sul?

Existe na América do Sul uma excepcionalidade, qual seja a ausência de conflitos militares prolongados entre os atores locais, entretanto, tal ausência de guerras não foi resultado da implantação de uma Comunidade Pluralista de Segurança ou Zona de Paz, o que levanta várias tensões explicativas nas epistemologias que tentam compreender a "longa paz [interestatal] sul-americana”. Em primeiro lugar, há dificuldades por parte das narrativas, o exemplo da Escola Inglesa e do Liberal Institucionalismo, em que se observaram inconsistências teóricas referentes a: (i) como tratar a artificial distinção institucional entre segurança e defesa; (ii) apesar do otimismo em mecanismos sobre o papel dos resolução de conflitos, como evitar que investimentos militares continuem a gerar dilemas de segurança; (iii) como entender o impacto de processos domésticos na segurança regional, sobretudo os alertados por indicadores que alertam para dimensões sociais que fragilizam o Estado sul-americano; (iv) e, por fim, como entender que a narrativa da guerra já não é o único elemento constitutivo dos estudos de segurança na América Latina, e que é necessário uma narrativa que necessariamente dê conta da violência social local com impactos transnacionais, quer dizer do lado escuro da sociedade internacional sul-americana.

O artigo fez um esforço analítica, baseado em dados empíricos, em mostrar como narrativas tradicionais, aqui ilustramos com o casos da Escola Inglesa e do Liberal Institucionalismo, são tencionadas, nas suas premissas, por processos empíricos que questionam os seus pressupostos teóricos da (longa) paz na América do Sul: primeiro, mostrando como tais narrativas continuam ainda muito presas e condicionadas por uma noção de paz negativa que prioriza uma perspectiva inter-estatal sul-americana de construção de paz; em segundo lugar, as narrativas tradicionais sobre paz na América do Sul são também tencionadas pela problemática da (in) diferenciação de políticas de segurança e defesa na região, isso aparece evidente na ausência de uma reflexão conceitual, por parte da tais perspectivas, na construção mais recente do multilateralismo referente àquela dicotomia, e nas temáticas relacionadas aos investimentos militares mais recentes. e finalmente, uma tenção latente aparece quando se examinam índices internacionais sobre violência e políticas públicas na região sul-americana: aqui aparece um quase paradoxo conceitual porque ao mesmo tempo que tais narrativas, sobretudo no caso da Escola Inglesa e do Institucionalismo Liberal, contribuíram com metodologias baseadas na sociologia histórica, acabam fazendo uma sociologia hisórica estatista da qual escapa uma reflexão sobre a violência social transacional e seus atores sociais e políticos e a forma como esta e estes, afetam a proposta normativa de tais perspectivas relativa à formação de um "Estado forte" sul-americano, condição normativa esta para a geração de uma sociedade anárquica de qualidade (positiva) na região. 
Finalmente, o artigo tentou mostrar mais uma tenção das narrativas tradicionais sobre paz na América do Sul: questiona-se versão conceitual sobre o dualismo ou hibridismo (Região Andina e Cone Sul) que diferentes visões epistemológicas ajudaram a construir.Ambas sub-regiões apresentam algumas características distintas na formação de instituições liberais, na formação política e social do estado (caso Brasil), e na percepções mais positiva ou mais negativa que um estado tem sobre o poder do outro porém ambas sub-regiões mantêm padrões semelhantes quanto às ameaças e debilidades estatais; bem como à permanência de questões tradicionais, como dilemas de segurança, internos e externos, derivados de conflitos políticos e sociais domésticos ou de investimentos militares nas Forças Armadas.

$\mathrm{O}$ artigo tenciona o discurso de epistemologia tradicionais de acordo com as quais coexistem na América do Sul sociedades anárquicas qualitativamente diferenciadas, uma com predominância de tradições, instituições e princípios que reforçam as narrativas epistemológicas sobre a construção da paz e de uma comunidade de segurança e outra, que incorpora um conteúdo qualitativo negativo da anarquia sul-americana, na qual ainda prevalecem significados e construções que remetem a paradoxos de segurança, práticas fortes de grupos sociais violentos e fragilidade estatal. Parece existir um esgotamento ou ponto de saturação conceitual dessas narrativas epistémicas tradicionais binomiais que, certamente, têm sido relevantes para solucionar dilemas conceituais, baseadas numa rica sociologia histórica, mas que vem esgotado sua principal dicotomia (paz versus guerra) e as quais precisam ser recicladas incorporando narrativas emergentes, a exemplo violência social regional, como novo elemento constitutivo essencial do internacional-regional na América do Sul.

\section{Referências}

Battaglino, J. (2012). The coexistence of peace and conflict in South America toward a new conceptualization of types of peace. Revista Brasileira de Política Internacional, 55(2), 131-151.

Bernal-Meza, R. (2010). International thought in the Lula era. Revista Brasileira de Política Internacional, 53(SPE), 193-213.

Bigo, D. (2001). The Mobbius of Internal and External Security. In: M. Albert, D. Jacobson \& Y. Lapid (eds.), Identities Borders Orders (pp. 91-136). Minneapolis and London: University Press of Minnesota.

Bull, H. (2002). A sociedade anárquica. Brasília: Editora Universidade de Brasília.

Buzan, B., Wæver, O., \& De Wilde, J. (1998). Security: A new framework for analysis. Lynne Rienner Publishers. 
Buzan, B. \& Weaver , O. (2003). Regions and Powers: The Structure of International Security. New York: Cambridge University Press.

Buzan, B., \& Wæver, O. (2009). Macrosecuritisation and security constellations: reconsidering scale in securitisation theory. Review of International Studies, 35(2), 253-276.

Colombo, S. (2012). La Unasur frente a las problemáticas que amenazan la gobernabilidad en la región. En: L. F. Ayerbe (org.) Territorialidades, conflitos e desafios à soberania estatal na América Latina. São Paulo: Fundação Memorial da América Latina.

Dangond, C. (2014). Gobernanza latinoamericana en materia de lucha contra las drogas. En: Buelvas, e.P. \& Gehring, H. Suramérica en el escenario global: gobernanza multinivel y birregionalismo. Bogotá: Editorial Pontifícia Universidad Javeriana.

Deutsch, K. \& Burrel, S. \& Kann, R. \& Lee, M. (1957). Political Community and the North Atlantic Area. Princeton: Princeton University Press.

Domínguez, J. (2007). International Cooperation in Latin America: The Design of Regional Institutions by Slow Accretion. In: A. Amitav \& I. J. Alastair (Eds.), Crafting Cooperation: Regional International Institutions in Comparative Perspective. New York: Cambridge University Press.

Herz, M. (2010). Construindo confiança na América Latina. En: M. Cepik, Segurança Internacional: práticas, tendências e conceitos. São Paulo: Editora Hucitec.

Holsti, K. (1996). The State, War, and the State of War. Cambridge: Cambridge University Press.

Hurrel, A. (1998). An emerging security community: in South America? In: E. Adler \& M. Barnet (Eds.), Security Communities (pp. 228-264). Cambridge: Cambridge University Press.

Hurrel, A. \& Woods, N. (1995). Globalisation and Inequality. Millenium, 24(3), 447-470.

Hurrel, A. \& Woods, N. (cords.) (1999). Inequality, Globalization and World Politics. Oxford: Oxford University Press.

Kacowicz, A. (1998). Zones of Peace in the Third World. South America in Comparative Perspective. Albany: State University of New York.

Kacowicz, A. M. (2005). The Impact of Norms in International Society: The Latin American Experience, 1881-2001. Notre Dame: University of Notre Dame Press.

Kelling, G. \& Coles, K. (1996). Fixxing Broken Windows: Restoring Order and Reducing Crime in Our Communities. New York: Touchstone Simon \& Shuster. 
Lindle, D. (2007). Promoting peace with information: Transparency as tool of the security regimes. Princeton: Princeton University Press.

Mares, D. (2001). Violent Peace. New York: Columbia University Press.

Mares, D. R. (2012). Por que os latino-americanos continuam a se ameaçarem. O uso da força militar nas relações intra latino-americanas. Varia historia, 28(48), 599-625.

Military Power Review (2014). Ranking do Poder Militar na América do Sul -[South American Military Power Ranking 2014], Military Power Review, www.militarypower.com.br/ranking.htm.

Miller, B. (2007) States, Nations, and the Great Powers. The Sources of Regional War and Peace. Cambridge: Cambridge University Press.

Oelsner, A. (2009). International Relations in Latin America: Peace and Security in the Southern Cone. London: Routledge.

Oelsner, A. (2007). Friendship, Mutual Trust and the Evolution of Regional Peace in the International System. Critical Review of International Social and Political Philosophy, 10(2), p. 257-279,

Pion-Berlin, D. \& Trinkunas, H. (2007). Attention Deficits: Why Politicians Ignore Defense Policy in Latin America. Latin American Research Review, 42(3), 76-100.

Saint-Pierre, H. (2013). Reflexiones sobre los estudios de defensa: perspectiva filosófica e histórica. En: J. A. Mora, Ciencias que uniforman el médio militar. Bogotá: Sello Editorial ESMIC.

Saint-Pierre, H. (2015). Breve Reflexión sobre el empleo de las Fuerzas Armadas. Revista Voces en el Fênix, 48, 14-21.

Seguridad, Justicia y Paz (2015). As 50 cidades mais violentas do mundo com mais de 300 mil habitantes. Disponível em: http://www.seguridadjusticiaypaz.org.mx/lib/ Prensa/2016_01_25_seguridad_justicia_y_paz-50_most_violent_cities_2015. pdf Acesso em 10 de dezembro de 2015.

Buzan, B., \& Wæver, O. (2009). Macrosecuritisation and security constellations: reconsidering scale in securitisation theory. Review of International Studies, 35(2), 253-276.

Trujillo, A. M. (2014). Estructuras de gobernanza multinivel de seguridad en Suramérica. En: E. Pastrana Buelvas \& H. Gehring, Suramérica en el escenario global: gobernanza multinivel y birregionalismo (pp. 183-200). Bogotá.

Transparency International (2000). Corruption Perception Index. Disponível em: http:// www.transparency.org/research/cpi/overview Acesso em 15 de Dezembro 2015. 
Tulchin, J. S., Manaut, R. B., \& Diamint, R. C. (Eds.). (2006). El rompecabezas: conformando la seguridad hemisférica en el siglo XXI. Buenos Aires: Prometeo.

Villa, R. D. (2008). Corrida armamentista ou modernizaça ̃ de armamentos na América do Sul: estudo comparativo dos gastos militares' [Arms race or modernization of armament in South America: a comparative study of military expenditures], Observatório Politico Sul-Americano, Rio de Janeiro, 2008, www. plataformademocratica.

Villa, R. A. D., \& Weiffen, B. (2014). South American Re-armament: From Balancing to Symbolizing Power. Contemporary Security Policy, 35(1), 138-162. 